\title{
Experimental Tribometric Characteristics Analysis of a Ferrofluid Based Journal Bearing System
}

\author{
Nimeshchandra S. Patel ${ }^{1)}$, G. M. Deheri ${ }^{2}$, H. C. Patel ${ }^{3)}$, K. R. Shah ${ }^{1)}$ and Atindra Shukla ${ }^{4)}$ \\ ${ }^{1)}$ Mechanical Engineering Department, Dharmsinh Desai University, Nadiad 387001, Gujarat, India \\ ${ }^{2)}$ Mathematics Department, Sardar Patel University, Vallabh Vidhynagar, Anand 388120, Gujarat, India \\ ${ }^{3)}$ Mathematics Department, L. D. College of Engineering, Ahmedabad, Gujarat, India \\ ${ }^{4}$ Shah Schulman Centre for Surface Science \& Nanotechnology, Dharmsinh Desai University, Nadiad 387001, Gujarat, India \\ *Corresponding author: Nimeshchandra S. Patel (nspatel.mech@ddu.ac.in)
}

Manuscript received 09 March 2020; accepted 12 June 2020; published 31 July 2020

Presented at 10th International Conference on Industrial Tribology (IndiaTrib - 2019), December 1-4, 2019

\begin{abstract}
This paper presents the tribometric characteristics analysis of a journal bearing system lubricated with ferrofluid (FF) considering different shaft materials. Two magnetically permeable materials namely, EN-19 and mild steel were used to manufacture the journal. These journals were made magnetic by inserting neodymium magnet inside. It was seen that the magnetic shaft made from EN19 offered a better dimensional accuracy in comparison with the magnetic shaft made from mild steel. Thus, magnetic shaft made from EN-19 was used in a brass bearing to evaluate various tribometric characteristics namely, fluid film pressure, fluid temperature rise, bearing vibrations, friction torque and wear at various conditions. The experimental results showed that the maximum pressure enhanced up to $84 \%$ in the case of FF based bearing system in comparison with conventional lubricant based system. Also, the film pressure was measured for newly acquired FF and the three years old FF to check the stability of the FF. It was found that almost no change in the pressure profile was observed. Further, the temperature rise was found to be less in FF based system while marginal difference in damping characteristic was observed. Moreover, tribometric characteristics such as friction and wear were also investigated and compared between FF based and oil based bearing system. A significant drop in friction torque was found in the case of FF based system. In addition, the wear loss due to the machine starts and stops was measured in lubricated condition for several systems using weight loss and stylus method. However, wear loss was found to be marginally increased in the FF based system, in comparison with the low viscous conventional fluid based system. It has been clearly established that the FF based system presented here, may turn out to be a better option from efficiency and stable system point of view.
\end{abstract}

\section{Keywords}

ferrofluid, journal bearing, film pressure and temperature, friction and wear

\section{Introduction}

$\mathrm{FF}$, in the focus of this analysis, is the fluid which can be effectively controlled, positioned or moved by a magnetic field of suitable strength. It is a colloidal suspension of ferric oxide particles having diameter ranging from $10 \mathrm{~nm}$ to $20 \mathrm{~nm}$ coated with a surfactant in an appropriate carrier fluid. The superior properties of the FF make it suitable for technical applications in everyday life. The stable suspension of FF was first synthesized by Papell in 1964 [1]. After stable synthesis by Papell, the area of FF proved to be a new emerging research field. Due to the smart rheological properties of the $\mathrm{FF}$, there are various types of uses of FF in different areas namely, mechanical bearings, sealing, heat transfer, and medicines etc. Concerning the FF lubrication from bearings point of view, various researchers developed the theory of FF lubrication by incorporating magnetic force resulting from a magnetic field into the Reynold's equation [25]. Thereafter, many researchers, during the last three decades carried out a number of theoretical and experimental studies regarding FF lubrication. These researchers have shown that magnetohydrodynamic bearings have several advantages over conventional bearings. Most studies out of these, dealt with the theoretical aspects of FF lubrication.

Sorge [6] and Chandra [7] investigated the finite and infinitely long journal bearings respectively, considering cavitation boundary conditions which were not considered in the earlier studies conducted by Tarapov [3] and Tiepi [8] for the analysis of journal bearings. Chang et al. [9] embarked on the combined theoretical and experimental study of fourpocket journal bearings lubricated with FF. It was established 
that the particle suspension in the FF provided higher pressure distribution and less temperature rise without any side leakage of the lubricant. Osman et al. [10] analyzed various journal bearing characteristics under FF lubrication by solving the Reynold's equation using finite difference method. In this analysis, magnetic force generated from magnetization was incorporated in to the Reynold's equation, considering nonNewtonian behavior of the FF. In contrast to Chang et al. [9], it was shown that the FF lubrication offered little effect on attitude angle and friction force in comparison with conventional lubricants. The flow behavior index indicates the degree of non-Newtonian characteristics of the fluids. The amount of load which the fluid film can carry without metal to metal contact (load bearing capacity) depends on the flow behavior index. Osman et al. [11] discussed the effect of FF lubrication along with design and flow parameters on the journal bearing performance considering different magnetic field models. It was concluded that the load bearing capacity and attitude angle decreased while frictional force and side leakage increased with increase in flow behavior index at high eccentricity. Moreover, various papers were published in which the performance analysis of journal bearings using analytical method were carried out considering infinitely short and long approximation to solve magnetohydrodynamic Reynold's equation [12-16]. Most of these investigations suggested improved performance of journal bearing under FF lubrication.

Another benefit of FF as lubricant in bearings is that it offers better dynamic characteristics in comparison with conventional bearings. Owing to this merit, vibration analysis of FF based bearing system became the focus of the study. Chao and Huang [17] analyzed the effect of FF lubrication in the herringbonegrooved journal bearing (HGJB) using numerical approach. Various rotor dynamic characteristics namely, stiffness, damping coefficient and critical speed were studied, in addition to pressure distribution. It was concluded that the use of FF in HGJB improved the bearing stiffness and widened the stability range. Miwa et al. [18] conducted an analysis of damping effect for a spindle in a FF based bearing. The damping characteristics of the bearing spindle was measured using high frequency vibration based ran through a piezo actuator. It was shown that the damping effect enhanced with increase in the spindle speed. Recently, many investigations talked of the dynamic characteristics of FF based systems [19, 20]. Many of these investigations showed improved damping characteristics of journal bearing lubricated with ferrofluids.

Furthermore, most studies on FF lubrication have analyzed the bearing performance theoretically and few have been examined experimental aspects. Some researchers examined several tribological properties experimentally of different bearing systems considering the lubricant as FF. Tribological characteristics namely, friction and wear found to be in main focus of many experimental investigations. Miyake and Takahashi [21] investigated friction and wear behaviour of a FF based sliding bearing. Experiments were conducted to find friction and wear using stationary cylindrical specimens made of permanent magnets which remained in contact with moving magnetic cylindrical objects. It was concluded that the friction force and wear reduced between the opposing specimens made from brass and PTFE under low and high operating speeds. Charles et al. [22] proposed the use of FF film bearings in the application of high precision rotary motion laser scanners due to its various improved properties like low power consumption, better stiffness and damping in comparison with conventional bearings. Li-jun et al. [23] demonstrated the tribological properties of Mn-Zn-Fe based magnetic fluid under magnetic field using four ball tester, SEM and EDS techniques. The reduction in wear scar was found to be almost $7.8 \%$ in the case of magnetic fluid lubrication under magnetic field in comparison with magnetic fluid lubrication without magnetic field. Also, the load carrying capacity and antifriction ability were observed to be greatly enhanced. Huang et al. [24] performed various tests to examine tribological performance of $\mathrm{Fe}_{3} \mathrm{O}_{4}$ based $\mathrm{FF}$ using ring-on cylinder tribometer considering ring and plate material as non-magnetic aluminum. It was shown that the load carrying capacity of magnetic fluid enhanced with increase in saturation magnetization. Also, friction coefficient was found to be less at $15.9 \mathrm{kA} / \mathrm{m}$ magnetization, in comparison with conventional fluid. Andablo-Reyes et al. [25] investigated friction behavior of magnetic nanofluids. It was shown that in mechanical bearings friction could be actively controlled by using magnetic nanofluids with suitable application of magnetization. Jianmei et al. [26] demonstrated the theoretical and experimental study of viscosity monitoring and control of FF as lubricant in oil film bearing. Results suggested that the negative influence of temperature on viscosity of FF could be neutralized by increasing the viscosity of FF under appropriate magnetic field. Recently, Patel et al. [27] investigated experimentally the pressure and temperature analysis of FF based journal bearing. A novel concept of magnetic journal bearing was implemented to magnetize the FF by using magnetic shaft and non-magnetic bearing. The shaft was made magnetic by inserting permanent magnet inside. It was concluded that the maximum film pressure enhanced and significant drop in temperature rise were seen in the case of FF based journal bearing. Further, Patel el al. [28] extended their analysis of FF based journal bearing made from different bearing materials with magnetic shaft. The pressure, temperature and wear analysis were carried out at various operating conditions. It was revealed that the combination of ferrous and non-ferrous metals for bearing and the shaft was found to be most suitable from enhanced performance of FF based journal bearing system point of view.

Until now, theoretical approach formed the basis of most of the investigations regarding FF lubrication. Very few papers have appeared on experimental aspects of FF based bearings covering the complete tribometric characteristics analysis. Besides, most experimental investigations have been carried out considering various tribo pairs under FF lubrication by providing magnetic field using electromagnet considering sample analysis. It is well-known that the friction and wear are system response. So, here considering the bearing design proposed by Patel et al. [27, 28], various tribometric characteristics were analyzed experimentally considering different magnetic shaft materials to enhance the effect of magnetic field on FF lubrication in the journal bearings. Moreover, the stability aspect of FF lubrication has also been discussed by measuring pressure considering old and new FF based journal bearing systems.

\section{Concept of the FF based journal bearing system}

Various methods have been proposed to magnetize the FF, which is a colloidal suspension of ferric oxide nano particles dispersed in a carrier liquid. These particles in a FF can be magnetized by applying external magnetic field using various methods. Many investigators analyzed FF lubrication by applying magnetic field in a different manner to magnetize 


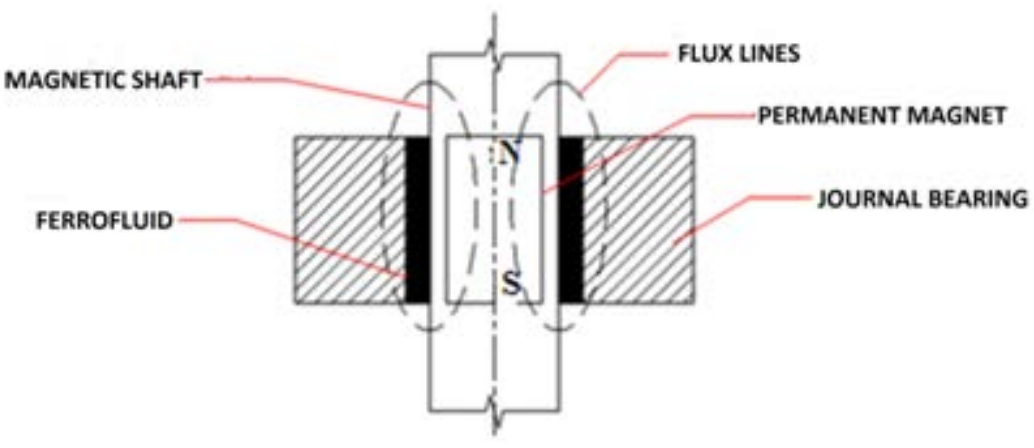

Fig. 1 Concept of the FF based journal bearing system

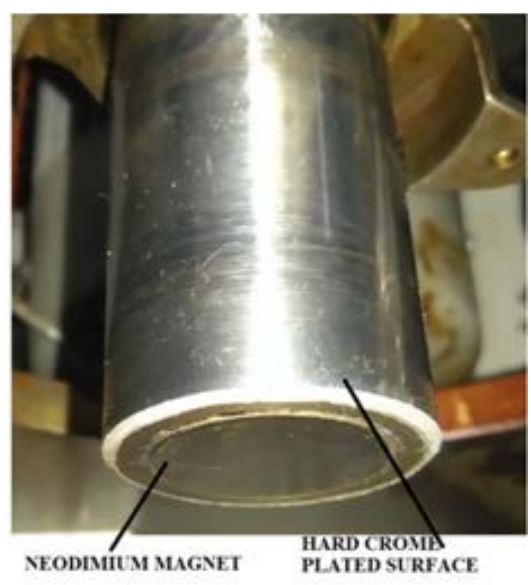

Fig. 2 EN-19 magnetic shaft

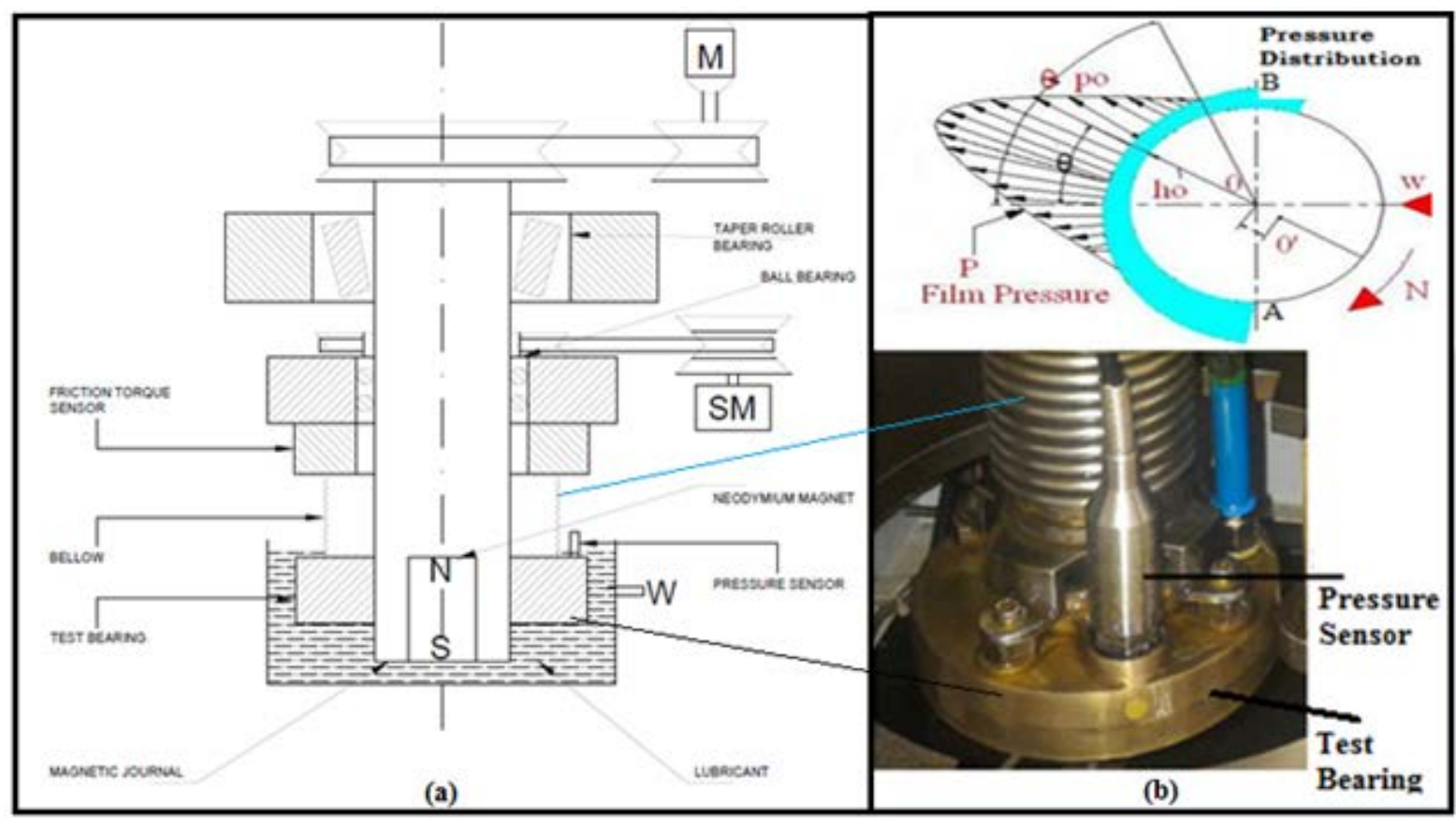

Fig. 3 (a) Schematic diagram of set-up (b) Pressure sensor mounted brass test bearing

the FF. But, most of the researchers used electromagnet in a FF based bearing system. These electromagnets are complicated from shape and size point of view and thus, may not be suitable in some machines. In view of that, Patel et al. [27, 28] suggested a novel method for magnetizing the FF by making shaft as magnetic rather than bearing as shown in Fig. 1. In the present analysis, efforts have been made to analyze various tribometric characteristics of a journal bearing system by making magnetic shaft and the bearing bushes from different materials. The magnetic shaft was manufactured by inserting a strong neodymium magnet inside the shaft as shown in Fig. 2. Test bearing made from brass as shown in Fig. 3b was used for pressure, temperature, vibration and friction analysis. The specifications of the bearing system have been presented in Table 1.

\section{Experimental details}

3.1 Experimental set up

Experiments were performed to investigate various
Table 1 Specifications of the journal bearing system

\begin{tabular}{c|c}
\hline Specifications & Brass bearing system \\
\hline Test Bearing Material & Brass $60-40$ \\
Shaft Materials & EN-19 \\
Bearing internal diameter & $40.14 \mathrm{~mm}$ \\
Journal diameter & $40.00 \mathrm{~mm}$ \\
Bearing length & $40 \mathrm{~mm}$ \\
Clearance & $0.07 \mathrm{~mm}$ \\
\hline
\end{tabular}

tribometric properties like film pressure, temperature rise, vibration, friction and wear of the present journal bearing system. For this purpose the journal bearing test-rig as shown in Fig. 3a was used and modified by changing the existing shaft by the magnetic shaft as per the requirements of the experimental investigation for FF based journal bearing system. In this set-up the shaft was kept vertical and rotates 
freely in the taper roller bearing using electric motor (M). The test bearing was suspended vertically from the friction torque sensor using flexible thin metallic bellow. This flexible bellow can transfer jerk sense by bearing due to friction to the friction torque sensor. The load (W) was applied on the test bearing perpendicular to the vertical shaft. The stepper motor (SM) rotated the test bearing around the shaft very slowly for the purpose of pressure measurement without affecting the shaft rotation. A proximity pressure sensor was mounted on the test bearing as shown in Fig. $3 \mathrm{~b}$ to measure the pressure created inside the bearing at various indexed positions. A $0.5 \mathrm{~mm}$ hole inside the bearing connected oil from central plane of test bearing to pressure sensor. The initial position of pressure sensor was kept at point A as shown in Fig. 3b from which bearing indexing started at very slow speed in the clockwise direction. After rotation of $9^{\circ}$, the indexing paused for a minute to acquire and display the pressure value on the controller. After pausing one minute, indexing continued for next 10 degree rotation to acquire pressure at the next position. This cycle continued till indexing angle reached position B as shown in Fig. 3. Using this method the pressure was obtained at 18 different positions using the pressure sensor in the loaded region. The pressure data so obtained in the controller was transmitted to the software in which the data were displayed as the pressure profile on the WINDUCOM 2010 software. The bulk temperature rise of the oil film was measured using digital thermometer near the loading point. Further, the friction force exerted on test bearing due to applied load and rotation of journal was measured by a strain gauge mounted above the test bearing as shown in Fig. 4. The system consists of an octagonal shaped component fixed with strain gauges. It was mounted to the bottom of free wheel mechanism and rotates along with it, and the test bearing was suspended from the bottom of this sensor on a metallic bellow. The rotation of journal created the jerk on the bearing in the direction of rotation, this motion was prevented by the strain gauge sensors and force was measured. Since the sensor arrangement was circular, the force measured was displayed in the form of torque [29]. It is well-known that the wear is a system response [30,31], here an attempt has been made to analyze wear loss on actual bearings during starts and stops of the machine which presents this as a better system response. Weight loss and surface roughness were obtained using weighing scale of accuracy $0.01 \mathrm{mg}$ and stylus meter as

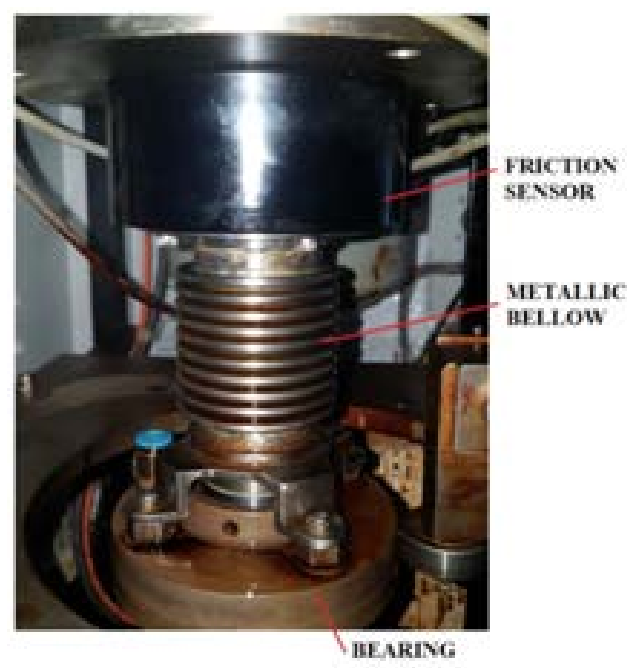

Fig. 4 Friction sensor

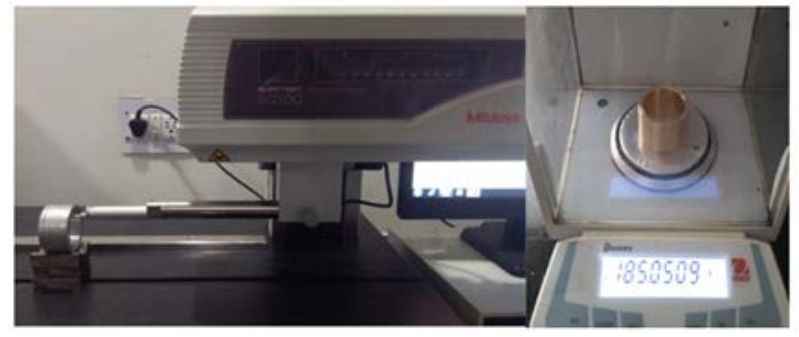

Fig. 5 Stylus meter and weighing scale

shown in the Fig. 5. To obtain the accurate weight, the bushes were washed in the petrol and kept them in the air for some time to rinse. The roughness was measured in the direction transverse to the machining lines on the bushes at a stylus speed of $1 \mathrm{~mm} / \mathrm{s}$. Finally, to check damping characteristics of the various lubricants the vibration was measured for different bearing systems. Here, vibration of the bearing was measured by installing velocity sensor on the loading lever which remains in contact with the bearing as shown in the Fig. 6 to get the enlarged effect of the vibration.

\subsection{Selection of bearing and shaft materials}

In a hydrodynamic journal bearing the oil film doesn't form properly during machine starting and stopping which results in severe wear of the bearings. Thus, the proper selection of the bearing material based on the service conditions is very important. In the FF based journal bearing system, Patel et al. [28] established a suitable combination of ferrous and nonferrous material for a FF based journal bearing system. The commonly used materials for journal are carbon steel and mild steel which are magnetically permeable and cost effective. Here, ferrous materials namely, carbon steel material EN-19 and mild steel which are magnetic in nature were chosen for making the shaft and test bearing was made from brass $60-40$ for film pressure, temperature and bearing vibration measurement. Shaft made from ferrous materials, shown in Fig. 2, was made magnetic by inserting neodymium permanent magnet of 30 $\mathrm{mm}$ diameter inside the $40 \mathrm{~mm}$ diameter journal. In this study, the purpose of using the magnetic steel was to magnetize the $\mathrm{FF}$ and to make external surface of the shaft magnetic. This will attract the FF towards the shaft surface as well as enhances the viscosity and decreases the side leakage. For wear analysis bearing bushes were manufactured from various commercial non-ferrous materials namely, aluminum (SAE6061), brass (IS319) and gunmetal as shown in Fig. 7.

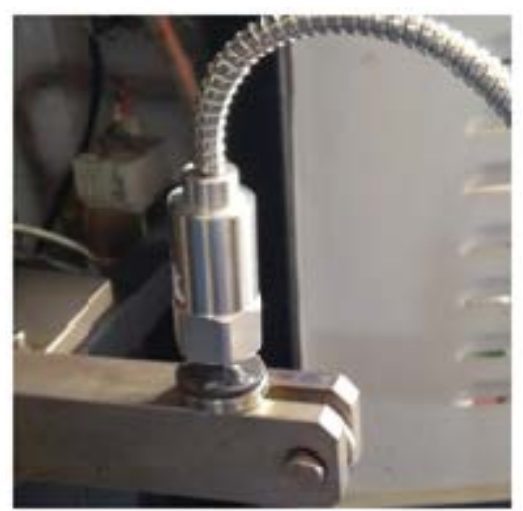

Fig. 6 Vibration sensor 


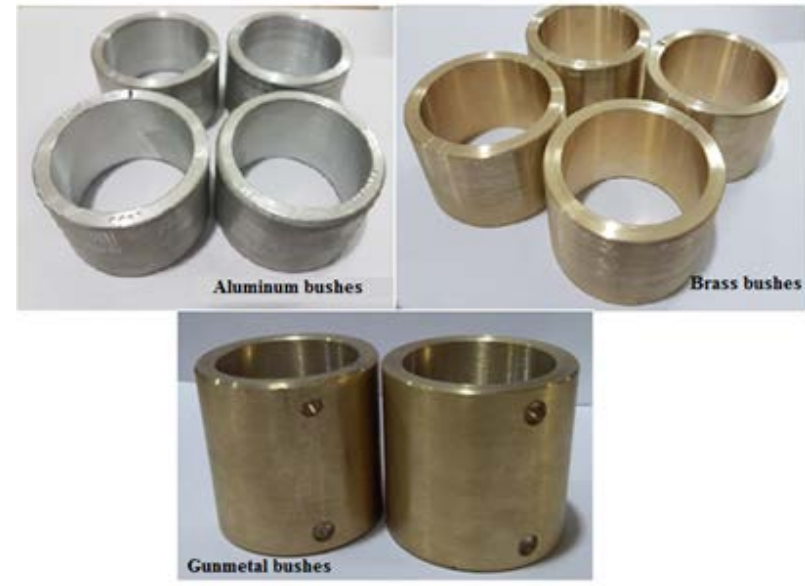

Fig. 7 Bearing bushes for wear analysis

\subsection{Properties of the lubricants}

For experimental analysis three different hydraulic oils were obtained from local Indian commercial market namely, ISOVG22, ISOVG32 and ISOVG46. FF was purchased from 'EDUCATIONAL INNOVATIONS, Inc, USA. The properties of various fluids used in the present analysis have been shown in Table 2. The hydraulic oils used in the present analysis are commonly used lubricants for bearings with anti wear additives and available in the market easily. Here, different viscosity based commercial oils were chosen so that the better comparison could be done with the ferrofluid from wear and other tribometric characteristics point of view.

\subsection{Test procedure}

As per the test requirements the experimental setup was modified by replacing the original shaft of the set-up by two magnetic shafts one by one. The film pressure was measured using brass $60-40$ test bearing for both the shafts. The film pressure distribution got distorted in the case of mild steel shaft due to ovality of the shaft surface as mild steel is very ductile material. This occurred while making hole inside the shaft due to the ductile nature of the mild steel. This problem occurred twice as the shaft was made from mild steel twice. Therefore, here the film pressure was measured considering EN-19 magnetic shaft based system for both three years old and the new FF to check the sedimentation effect on the film pressure at various operating conditions. Also, film pressure was obtained for ISOVG46 oil for comparing it with the FF. During pressure measurement bearing vibrations were also measure using vibration sensor. Further, temperature rise of oil film was measured by running the set-up for 3-hours continuously at $450 \mathrm{~N}$ applied load and journal speed of $500 \mathrm{rpm}$ considering four different lubricants based bearings namely, ISOVG22, ISOVG32, ISOVG46 and FF. During the long-run of 3-hours bulk temperature rise of various bearing systems were obtained using digital thermocouple. In addition, friction torque of these bearing systems was measured using friction sensor at various operating conditions. Moreover, wear analysis was conducted at the beginning using bearings made from gunmetal under fully submerged conditions resorting to frequent machine starts and stops. Initially wear loss was measured for gunmetal bearings using stylus method by measuring roughness before and after the 50 starts and stops under FF and ISOVG46 lubricants at $300 \mathrm{~N}$ load and 500 rpm speed. Additionally, from weight loss measurement point of view the bearing bushes were manufactured from slightly softer materials like brass and aluminum. Also, to increase the bearing pressure the bush size was decreased and tested at 500 rpm and $450 \mathrm{~N}$ load for 150 starts and stops. Wear loss of brass and aluminum bearings was measured by both the weight loss and using stylus method by measuring roughness before and after the 150 starts and stops under FF and various different viscosity lubricants. Finally, microscopic images were obtained for aluminum and brass bushes before and after the 150 starts and stops under different lubricating conditions. To see the wear pattern, the images of the wear out part of the surfaces were captured using microscope of 10x magnification. These images were used to confirm the wear obtained by the weight loss and surface roughness data for the better judgment.

\section{Results and discussion}

For complete analysis of the magnetic shaft based journal bearing system under different lubricating conditions, various tribometric characteristics were measured and analyzed experimentally.

4.1 Measurement of film pressure and bearing vibrations

Oil film pressure in the journal bearing system is one of the most important parameter from performance and life period point of view. Insufficient pressure may lead to more friction and wear of the system due to the direct metal to metal contact. So, initially in this analysis the pressure distribution was measured at various speeds and applied loads using proximity pressure sensor for two different oil based systems namely, FF and the ISOVG46 oil. The comparison of pressure between $\mathrm{FF}$ and conventional oil based bearing system are presented in Figs. 8-12 as well as in Table 3. It is observed that the maximum pressure occurs in the case of FF based bearing system as compared to oil based system. At most operating conditions the

Table 2 Properties of conventional fluids and FF

\begin{tabular}{ccccccc}
\hline $\begin{array}{c}\text { Name of the } \\
\text { fluid }\end{array}$ & $\begin{array}{c}\text { Density } \\
\mathbf{( k g / \mathbf { m } ^ { 3 } )}\end{array}$ & $\begin{array}{c}\text { Viscosity } \\
\text { Centipoise }\end{array}$ & $\begin{array}{c}\text { Saturation } \\
\text { Magnetization } \\
(\mathbf{m} \mathbf{)})\end{array}$ & $\begin{array}{c}\text { Volume fraction } \\
\text { of magnetites }\end{array}$ & Make & Item Code \\
\hline FF & $\begin{array}{c}1211 \\
\text { at } 27^{\circ}\end{array}$ & $\begin{array}{c}6 \\
\text { at } 27^{\circ}\end{array}$ & 44 & $3-15 \%$ & Ferrotec, USA & EFH-1 \\
ISOVG46 & $\begin{array}{c}882 \\
\text { at } 15^{\circ}\end{array}$ & $\begin{array}{c}46 \\
\text { at } 40^{\circ}\end{array}$ & 0 & 0 & Veedol, India & AVALON 46 \\
ISOVG32 & $\begin{array}{c}882 \\
\text { at } 15^{\circ}\end{array}$ & $\begin{array}{c}32 \\
\text { at } 40^{\circ}\end{array}$ & 0 & 0 & Veedol, India & AVALON 32 \\
ISOVG22 & 866 & $\begin{array}{c}22 \\
\text { at } 40^{\circ}\end{array}$ & 0 & 0 & $\begin{array}{c}\text { Bharat } \\
\text { Petrolium, India }\end{array}$ & $\begin{array}{c}\text { BRILLIANT } \\
\text { ISOVG22 }\end{array}$ \\
\hline
\end{tabular}




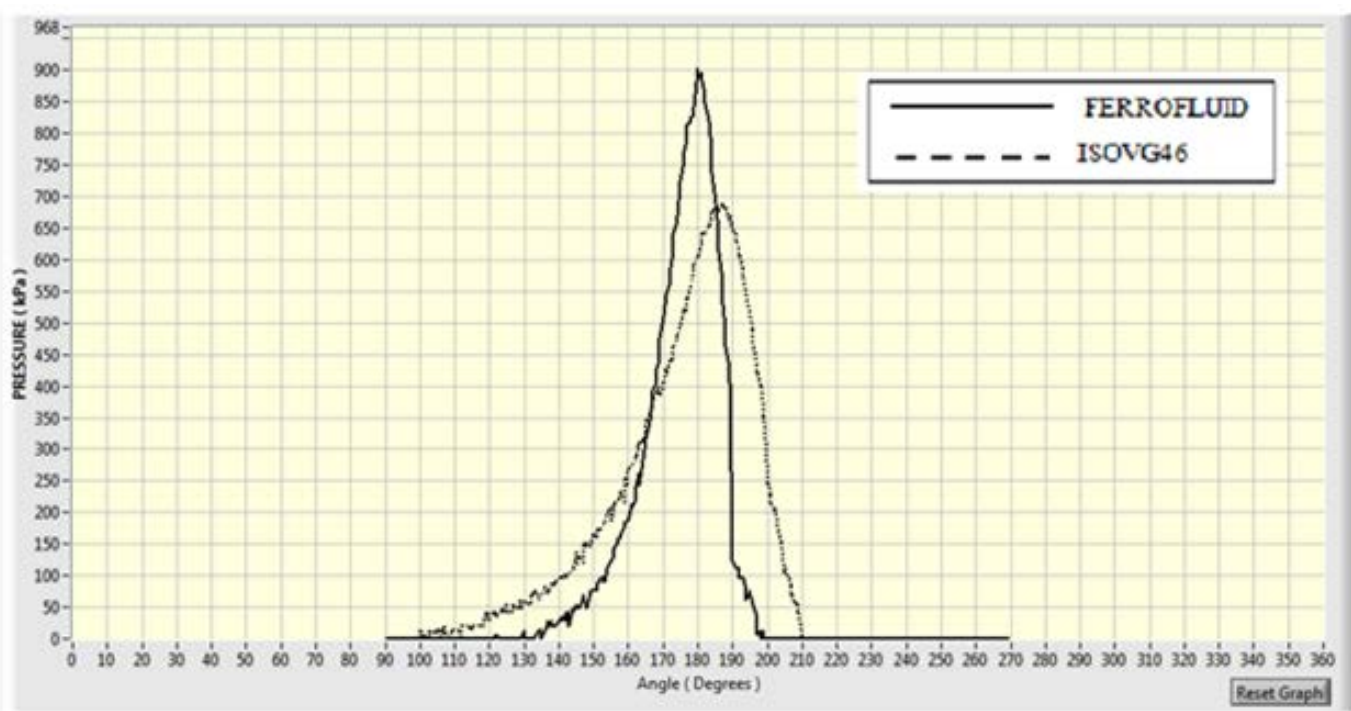

Fig. 8 Film pressure distributions of FF based and ISOVG46 based bearings at $250 \mathrm{rpm}$ and $300 \mathrm{~N}$ load

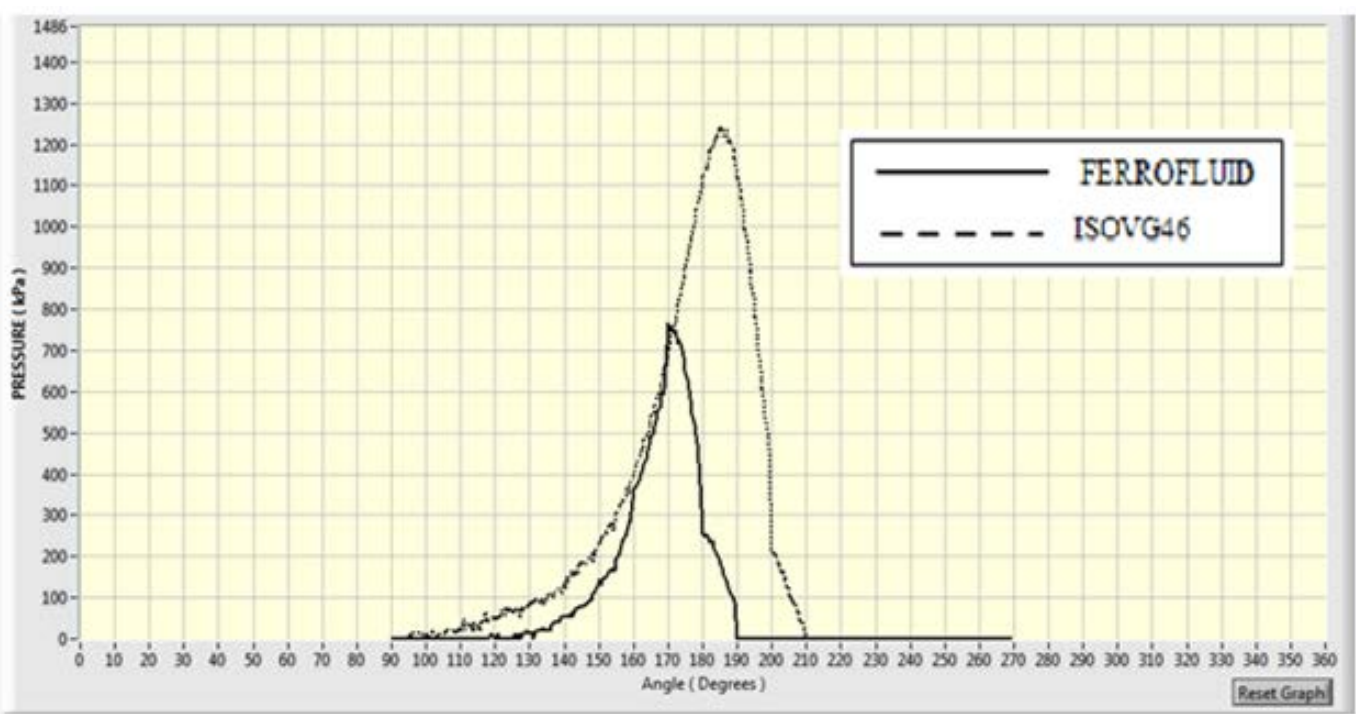

Fig. 9 Film pressure distributions of FF based and ISOVG46 based bearings at $250 \mathrm{rpm}$ and $450 \mathrm{~N}$ load

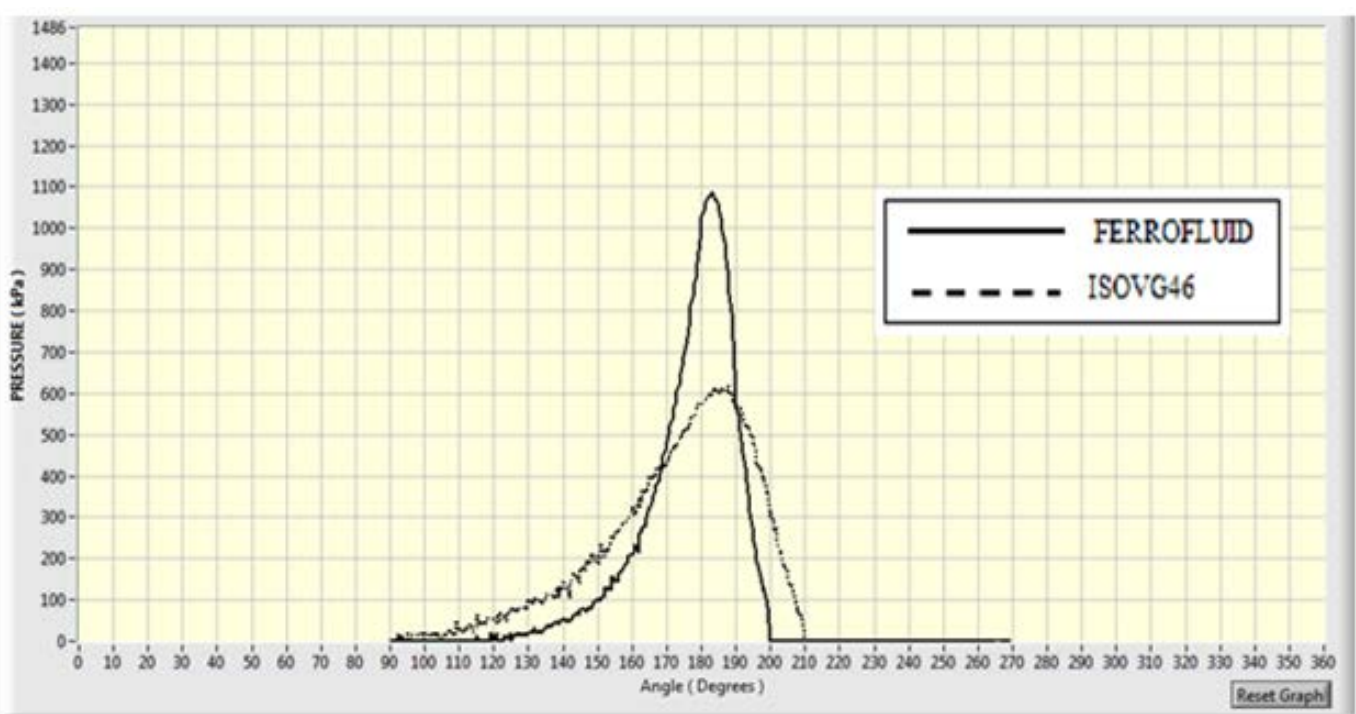

Fig. 10 Film pressure distributions of FF based and ISOVG46 based bearings at $500 \mathrm{rpm}$ and $300 \mathrm{~N}$ load 


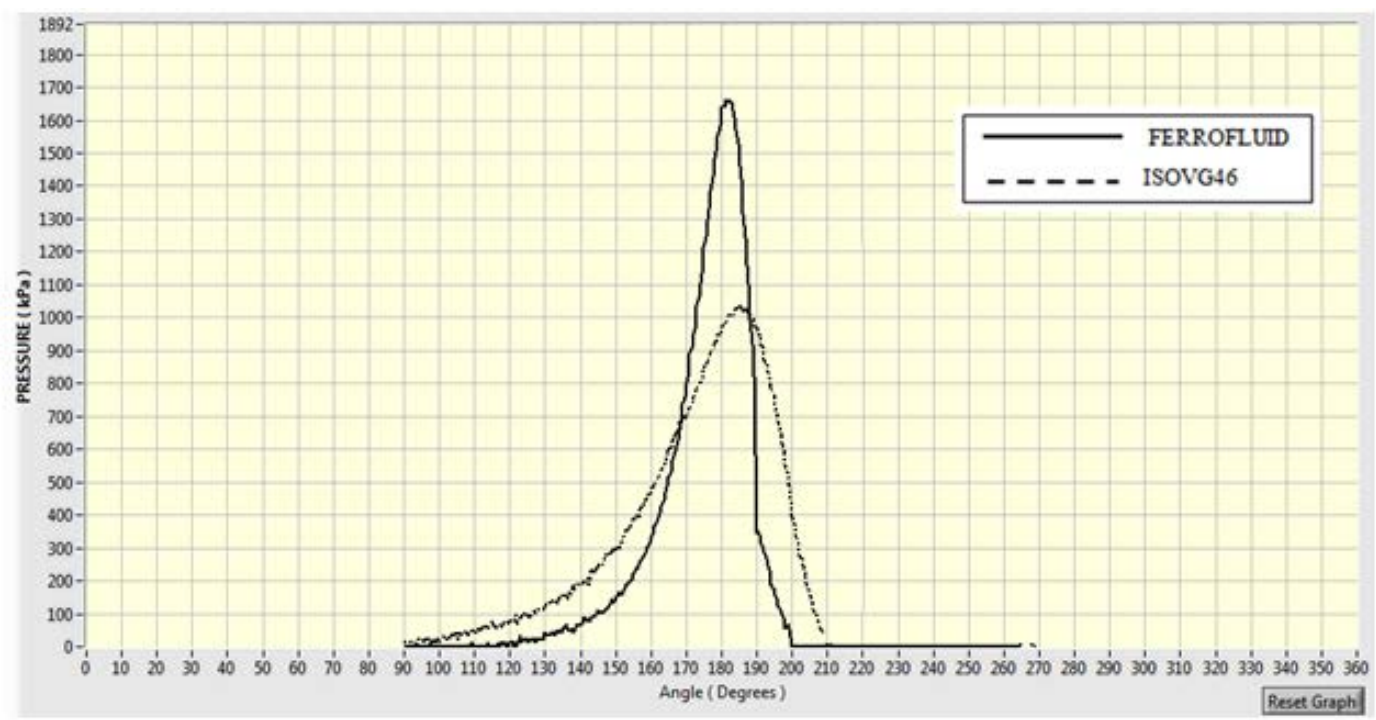

Fig. 11 Film pressure distributions of FF based and ISOVG46 based bearings at $500 \mathrm{rpm}$ and $450 \mathrm{~N}$ load

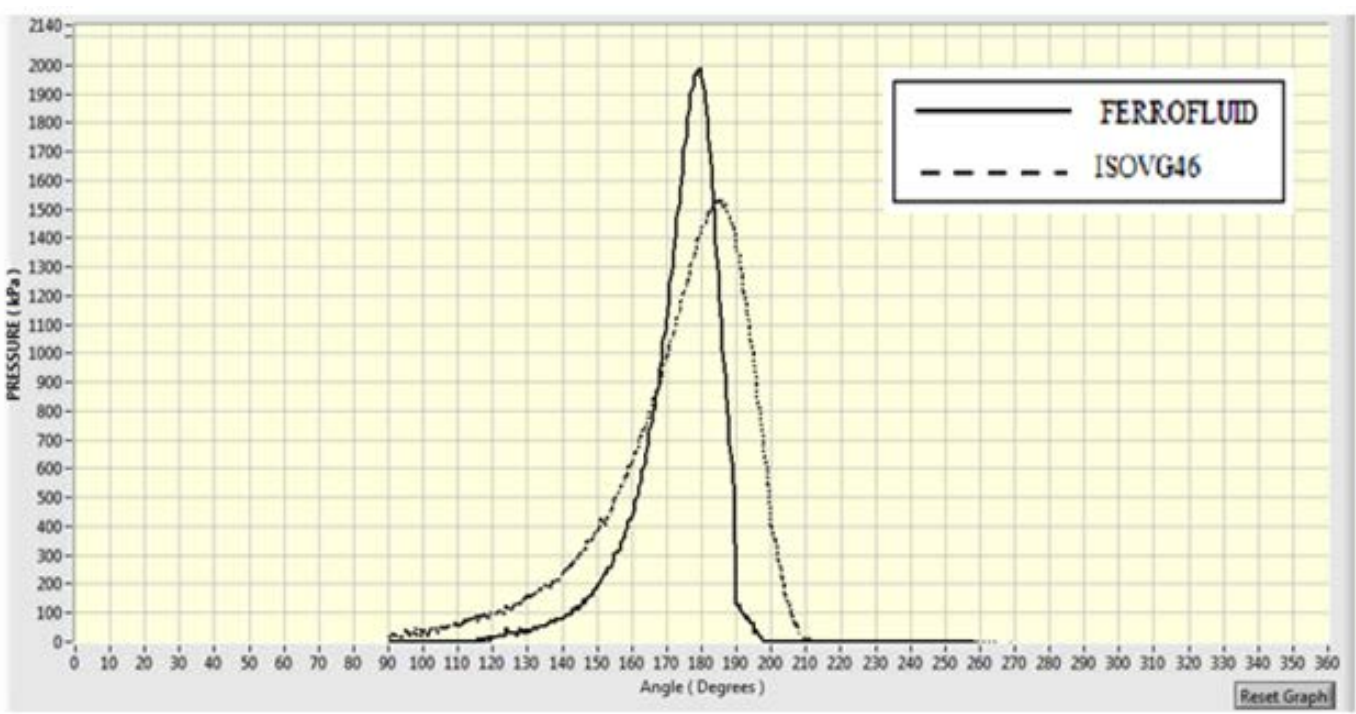

Fig. 12 Film pressure distributions of FF based and ISOVG46 based bearings at $500 \mathrm{rpm}$ and $600 \mathrm{~N}$ load

Table 3 Film pressures and bearing vibrations comparison in EN-19 shaft based brass bearing system

\begin{tabular}{|c|c|c|c|c|c|c|}
\hline $\begin{array}{l}\text { Sr. } \\
\text { No. }\end{array}$ & $\begin{array}{c}\text { Applied } \\
\text { Radial Load } \\
\text { N }\end{array}$ & $\begin{array}{c}\text { Journal } \\
\text { Speed } \\
\text { rpm }\end{array}$ & $\begin{array}{l}\text { Maximum } \\
\text { Pressure kPa } \\
\text { (FF based } \\
\text { lubrication) } \\
\end{array}$ & $\begin{array}{c}\text { Maximum Pressure } \\
\text { kPa } \\
\text { (ISOVG } 46 \text { oil } \\
\text { based lubrication) }\end{array}$ & $\begin{array}{c}\text { Bearing vibrations } \\
\text { in } \mathrm{mm} / \mathrm{s} \\
\text { (FF based } \\
\text { lubrication) }\end{array}$ & $\begin{array}{c}\text { Bearing vibration } \\
\text { in } \mathrm{mm} / \mathrm{s} \\
\text { (ISOVG } 46 \text { oil } \\
\text { based lubrication) }\end{array}$ \\
\hline 1 & 300 & 250 & 903 & 689 & 0.1 & 0.0 \\
\hline 2 & 450 & 250 & 765 & 1241 & 0.6 & 0.1 \\
\hline 3 & 300 & 500 & 1090 & 620 & 1.5 & 1.5 \\
\hline 4 & 450 & 500 & 1662 & 1234 & 2.3 & 2.4 \\
\hline 5 & 600 & 500 & 1992 & 1531 & 3.3 & 4.0 \\
\hline
\end{tabular}

maximum pressure is found to be more in the case of FF based system. This pressure enhancement occurs due to the viscosity enhances in the presence of magnetization in case of FF. Further, sharp enhancement in pressure may be obtained owing to less side leakage under magnetic field. From Fig. 10, it is observed that the enhancement in the pressure in case of FF is obtained almost $84 \%$ more in comparison with the ISOVG46 lubricant based system. The load carrying capacity was also calculated using Trapezoidal rule of integration. It was found that the load carrying capacity varied with change in operating conditions. In 
the present study up to $14 \%$ increase in load carrying capacity in case of FF has been obtained from the pressure profiles as seen in Fig. 10. This enhancement is registered to be more than the pressure enhancement claimed by Patel et al. [27] in the case of AISI410 magnetic shaft based bearing system. However, beyond $450 \mathrm{~N}$ load at $250 \mathrm{rpm}$ FF based system may turn to be in the boundary lubrication region. At this condition the significant $40 \%$ drop in load carrying capacity has also been reported. This clearly shown that the FF based system present here may not perform well at low speed and high load. Moreover, to analyze the effect of aging in the FF, on pressure distribution, the pressure are measured in the case of new FF based system and three years old used FF based system. From Figs. 13-16 and Table 4 it is clearly observed that there is almost no change in pressure distribution. Besides, to check the sedimentation of ferric oxide particles in the FF, the DLS test was carried out for old and the new FFs. Figure 17 shows the size distribution of the old and new FF samples. The older sample referred to measurement after three years period from initial usage.
The overlapping of distribution graphs conform almost same particle size for both these cases. Accordingly, it can be inferred that the employed FF is considerably stable. Furthermore, due to change in temperature viscosity of the fluid also changes. The vibration of the journal inside the bearing mainly, depends on the viscosity of the fluid. More vibrations may lead to the failure of the system due to direct contact of the shaft with the bearing. It is noticed from Table 3 that the vibration is found marginally less in the case of FF based system as compared to ISOVG46 based system except at high load $450 \mathrm{~N}$ and low speed of 250 rpm. This increased vibrations occurred due to the shifting of FF based system in to the boundary lubrication region.

\subsection{Temperature analysis}

The stability of the hydrodynamic journal bearing system also depends a lot on the temperature of the oil film. So, the analysis of temperature is very crucial for the present FF based system. In this analysis, temperature rise of fluid film at the bearing and shaft interface near loading point was measured

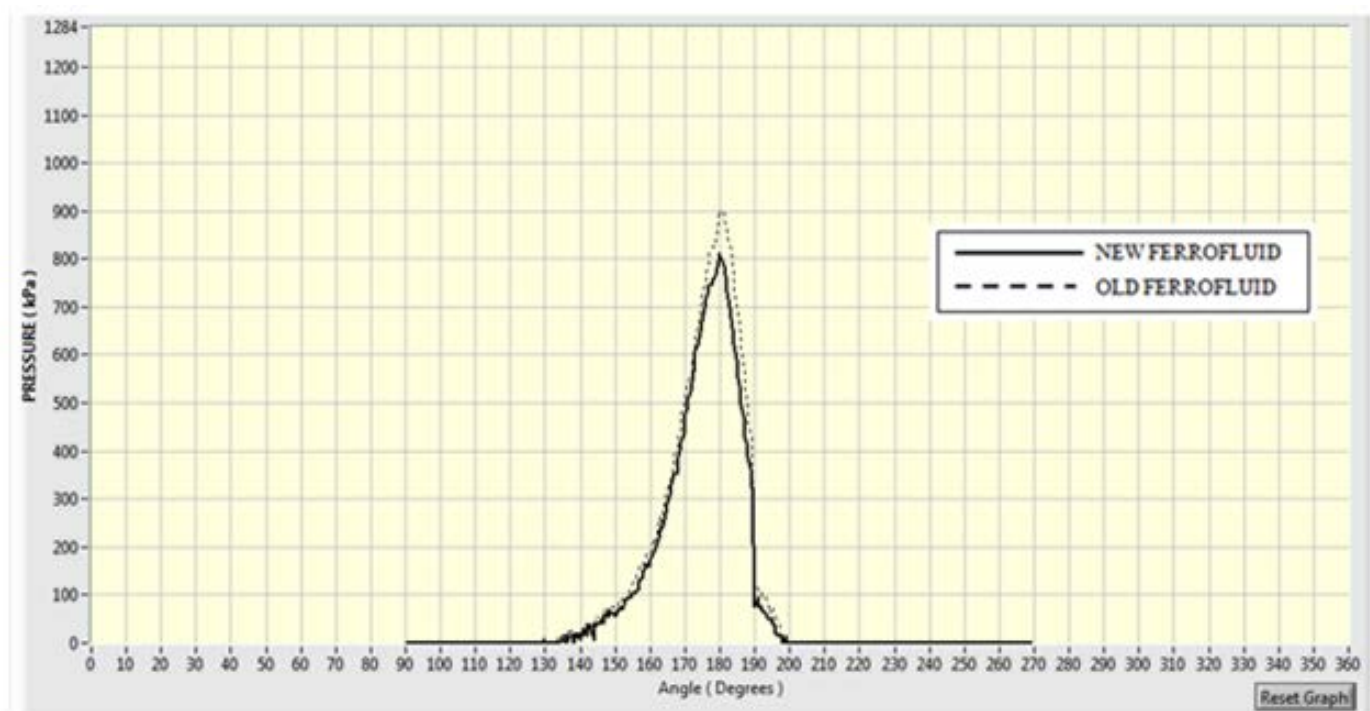

Fig. 13 Film pressure distributions of old and new FF based bearings at $250 \mathrm{rpm}$ and $300 \mathrm{~N}$ load

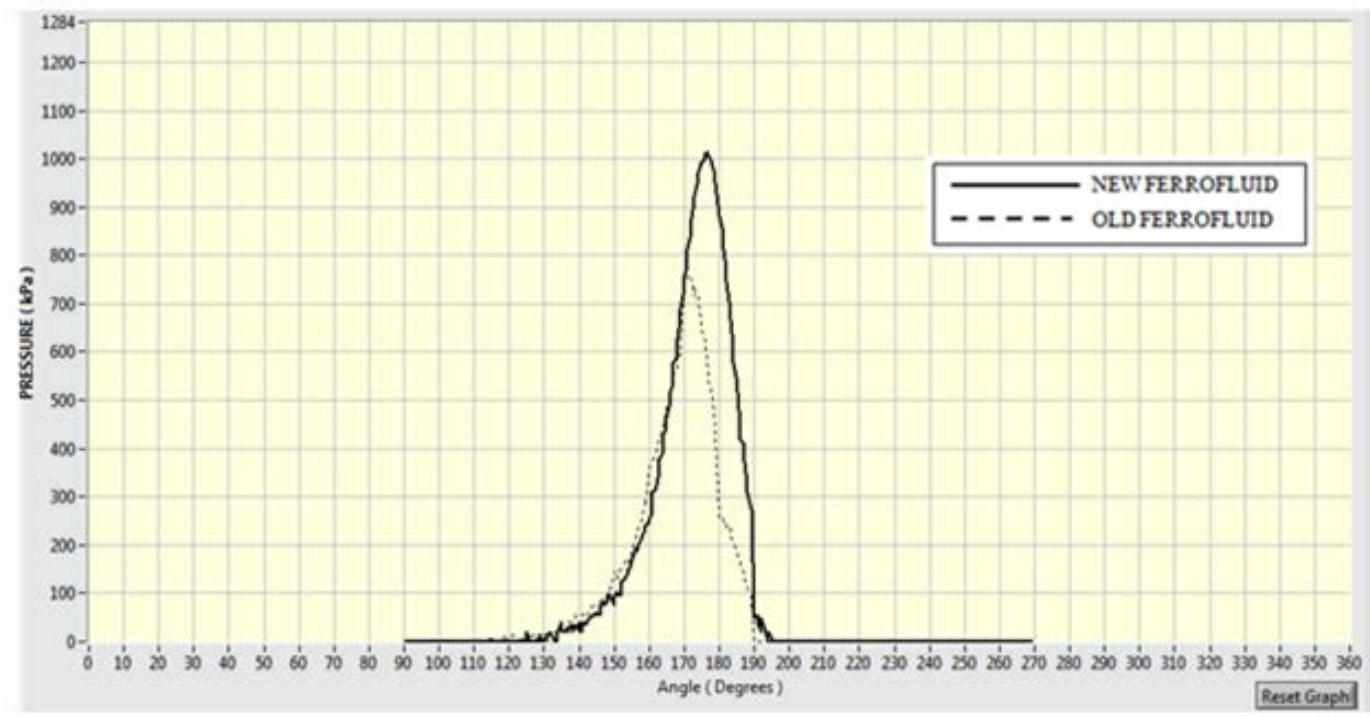

Fig. 14 Film pressure distributions of old and new FF based bearings at $250 \mathrm{rpm}$ and $450 \mathrm{~N}$ load 


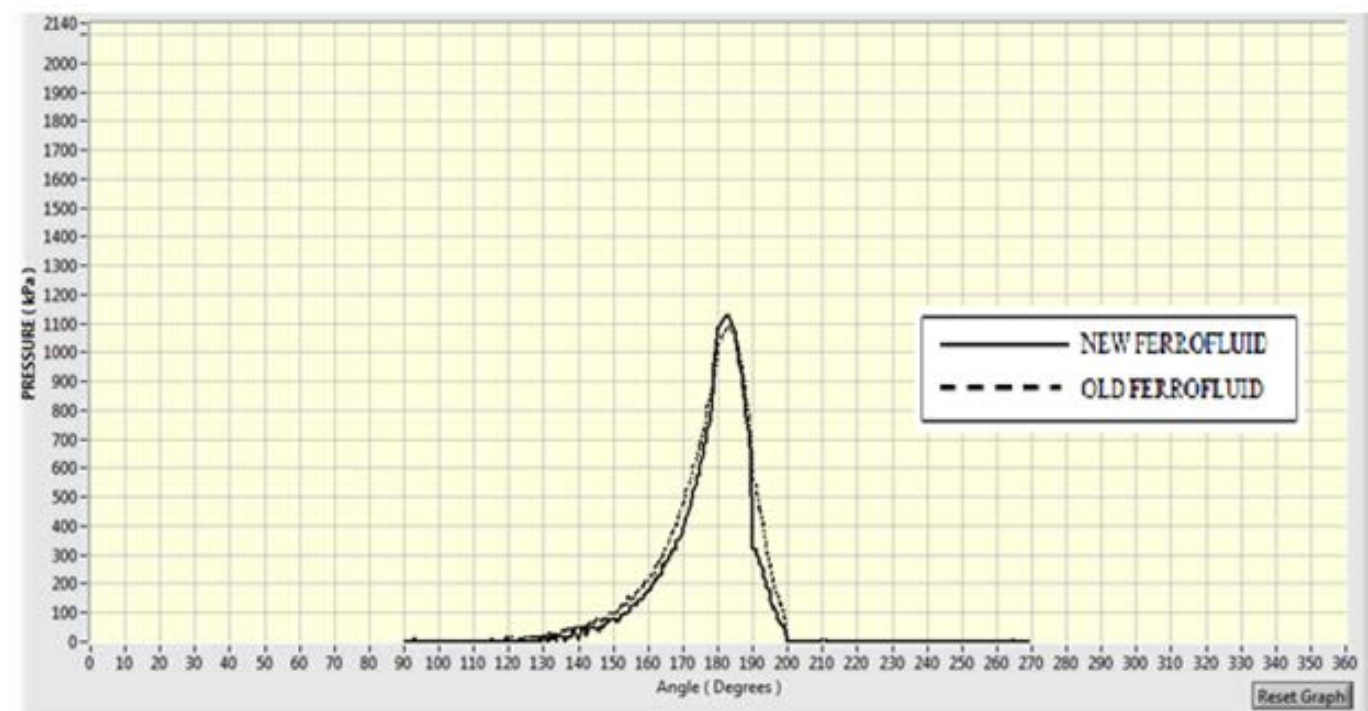

Fig. 15 Film pressure distributions of old and new FF based bearings at $500 \mathrm{rpm}$ and $300 \mathrm{~N}$ load

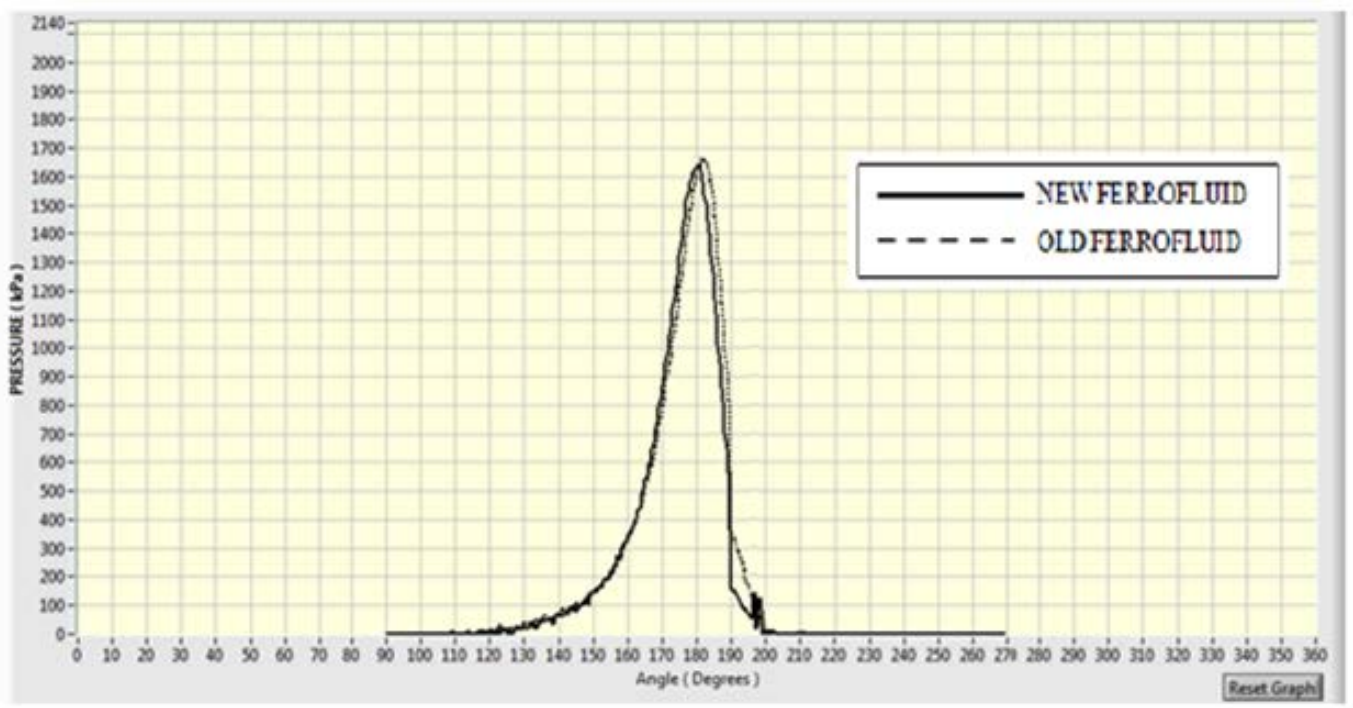

Fig. 16 Film pressure distributions of old and new FF based bearings at $500 \mathrm{rpm}$ and $450 \mathrm{~N}$ load

Table 4 Film pressure comparison in EN-19 shaft based brass bearing system for old and new FF

\begin{tabular}{cccccc}
\hline $\begin{array}{c}\text { Sr. } \\
\text { No. }\end{array}$ & $\begin{array}{c}\text { Applied } \\
\text { Radial Load } \\
\mathbf{N}\end{array}$ & $\begin{array}{c}\text { Journal Speed } \\
\text { rpm }\end{array}$ & $\begin{array}{c}\text { Maximum Pressure } \\
\mathbf{k P a} \\
\text { (OLD FF based } \\
\text { lubrication) }\end{array}$ & $\begin{array}{c}\text { Maximum Pressure } \\
\mathbf{k P a} \\
\text { (NEW FF based } \\
\text { lubrication) }\end{array}$ & $\begin{array}{c}\text { Maximum Pressure } \\
\text { kPa } \\
\text { (ISOVG46) }\end{array}$ \\
\hline 1 & 300 & 250 & 903 & 814 & 689 \\
2 & 450 & 250 & 765 & 1013 & 1241 \\
4 & 300 & 500 & 1090 & 1131 & 620 \\
5 & 450 & 500 & 1662 & 1634 & 1034 \\
\hline
\end{tabular}

considering different lubricant based system. To measure temperature rise beyond steady state condition all the bearing systems were made to run for 3 hours continuously. It is clearly seen from Fig. 18 that the temperature rise in the case of FF based system is observed significantly less in comparison with ISOVG22, ISOVG32 and ISOVG46 lubricant based system at 500 rpm journal speed and $450 \mathrm{~N}$ applied load. Approximately $40 \%$ less temperature rise in the case of FF based system is obtained. Probably, this may be due to the higher thermal conductivity of FF due to the presence of ferric oxide nano particles [32]. The change in temperature of ferrofluid is found very less and hence the effect of temperature on viscosity could be neglected in case 


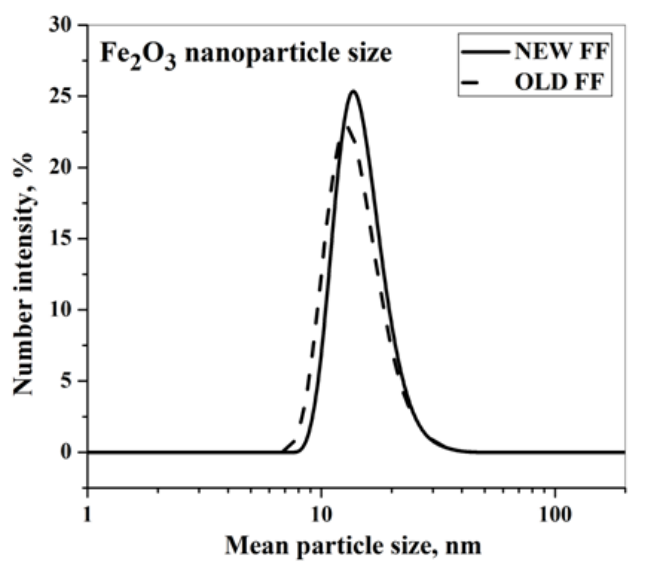

Fig. 17 Particle analysis using DLS of old and new FF

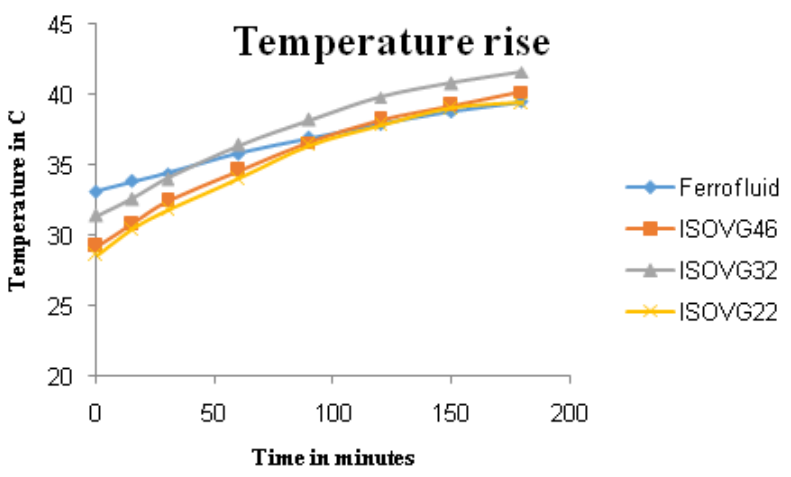

Fig. 18 Temperature rise in different lubricant based bearings for 3 hours long run

of ferrofluid based bearing system.

\subsection{Friction analysis}

It is well-known that the overall efficiency of a hydrodynamic journal bearing system depends on the friction offered by lubricants and metal to metal contacts between the bearing and the journal. But, in properly designed hydrodynamic journal bearing, efficiency of the bearing system depends on the friction offered by the fluid. So, in the present journal bearing system friction was measured using friction torque sensor in the hydrodynamic conditions at $300 \mathrm{~N}$ and 450 $\mathrm{N}$ load at $500 \mathrm{rpm}$ journal speed. It is revealed from Table 5 that the friction torque found significantly less at all the conditions in the case of FF based system in comparison with conventional lubricants based systems. Possibly, this could be because of the rolling effect due to presence of nano particles between the fluid layers in hydrodynamic conditions [24]. The low viscosity of FF could be another reason but in the present study the ferrofluid was used as a lubricant in the presence of magnetic field. And, it is well-known that the viscosity of the ferrofluid increases in the presence of magnetic field.

\subsection{Wear analysis}

After having improved performance of the present FF based bearing system, from life period point of view wear analysis was conducted. In properly lubricated hydrodynamic conditions complete separation of the bearing and the shaft occurs, which results in negligible wear. However, the life of the hydrodynamic journal bearing mainly depends on the wear occurrence during starts and stops of the machine because an intensive metal to metal contact occurs during starting and stopping of the machine owing to improper formation of the film pressure [33]. So, here wear analysis was conducted by manufacturing bearing bushes from different materials. The cylindricity may play an important role in wear of metal surfaces and hence the bushes were manufactured with utmost care to avoid the ovality in the bushes. Besides, hard chrome plating was applied on the journal surface to prevent any kind of wear loss on the shaft surface. Initially, bearings were manufactured from gunmetal of $40 \mathrm{~mm}$ diameter and $50 \mathrm{~mm}$ length. These bearings were rubbed against the shaft at 500 rpm and $300 \mathrm{~N}$ load for 50 starts and stops of the machine. The roughness of the bearings was measured before and after the wear test. It is seen from Table 6 that the change in roughness occurred more in the case of FF based bearing in comparison with ISOVG46 based bearing. Wear loss in terms of weight difference was not found clearly due to heavy weight of the gunmetal bush and minor weight loss. So, to analyze wear loss beyond running in the bearing bushes were manufactured of slightly smaller dimensions $40 \mathrm{~mm}$ diameter and $30 \mathrm{~mm}$ length from softer non-ferrous materials like aluminum and brass as seen in Fig. 7. Also, applied load increased to $450 \mathrm{~N}$ and number of starts and stops increased to 150 to quantify wear beyond running in measuring weight loss and difference in roughness [34]. As can be seen from Table 7 that the weight loss is noticed to be more in the case of FF based system as compared to more viscous conventional fluid ISOVG32 and ISOVG46 based systems. However, marginal difference in wear loss is obtained in comparison with the less viscous ISOVG22 fluid based system. Further, the wear analysis was also conducted by measuring surface roughness and taking microscopic images before and after the wear test. Roughness was measured at three different locations in the loaded region of the bearings before and after the test. Thereafter, the average roughness was calculated from the comparison point of view. It is seen from Table 6 that the difference in roughness found almost same in the case of FF based aluminum bearing and ISOVG22 based aluminum bearing. The roughness difference is found less in highly viscous ISOVG46 fluid based aluminum and brass bearings. The roughness in case of ISOVG22 and ISOVG32 based system was found more after the wear test which in turn resulted in more roughness after the wear. This could be due

Table 5 Friction torque comparison between various fluids with FF

\begin{tabular}{lcccccc}
\hline $\begin{array}{l}\text { Sr. } \\
\text { No. }\end{array}$ & $\begin{array}{c}\text { Applied } \\
\text { Radial Load } \\
\mathbf{N}\end{array}$ & $\begin{array}{c}\text { Journal Speed } \\
\text { rpm }\end{array}$ & $\begin{array}{c}\text { Friction torque } \\
\text { N-mm } \\
\text { (FF based lubrication) }\end{array}$ & $\begin{array}{c}\text { Friction torque } \\
\text { N-mm } \\
\text { (ISOVG 46 oil } \\
\text { based lubrication) }\end{array}$ & $\begin{array}{c}\text { Friction torque } \\
\text { N-mm } \\
\text { (ISOVG 32 oil } \\
\text { based lubrication) }\end{array}$ & $\begin{array}{c}\text { Friction torque } \\
\text { N-mm } \\
\text { (ISOVG 22 oil } \\
\text { based lubrication) }\end{array}$ \\
\hline 1 & 300 & 500 & 07 & 80 & 39 & 14 \\
2 & 450 & 500 & 42 & 195 & 146 & 115 \\
\hline
\end{tabular}


Table 6 Change in roughness of various journal bearings for 150 machine starts and stops under different lubricating conditions

\begin{tabular}{cccccc}
\hline $\begin{array}{c}\text { Sr. } \\
\text { No. }\end{array}$ & Bearing material & Lubricant & $\begin{array}{c}\text { Roughness (Ra) } \\
\text { before wear test } \\
\text { in } \boldsymbol{\mu m}\end{array}$ & $\begin{array}{c}\text { Roughness (Ra) } \\
\text { after wear test } \\
\text { in } \boldsymbol{\mu m}\end{array}$ & $\begin{array}{c}\text { Ra Difference } \\
\text { in } \boldsymbol{\mu m}\end{array}$ \\
\hline $\mathbf{1}$ & Gunmetal & FF & 5.8164 & 4.5735 & 1.2429 \\
$\mathbf{2}$ & Gunmetal & ISOVG46 & 6.0561 & 5.8643 & 0.1918 \\
$\mathbf{3}$ & Aluminum & FF & 2.5425 & 1.9663 & 0.5762 \\
$\mathbf{4}$ & Aluminum & ISOVG46 & 3.8205 & 3.4734 & 0.3471 \\
$\mathbf{5}$ & Aluminum & ISOVG32 & 3.4746 & 3.3564 & 0.1182 \\
$\mathbf{6}$ & Aluminum & ISOVG22 & 3.9443 & 3.3084 & 0.6359 \\
$\mathbf{7}$ & Brass & FF & 2.4327 & 1.1868 & 1.2459 \\
$\mathbf{8}$ & Brass & ISOVG46 & 2.8478 & 2.8040 & 0.0438 \\
$\mathbf{9}$ & Brass & ISOVG32 & 2.8304 & 2.8389 & -0.0085 \\
$\mathbf{1 0}$ & Brass & ISOVG22 & 2.6667 & 2.6861 & -0.0194 \\
\hline
\end{tabular}

Table 7 Material loss in various journal bearings for 150 machine starts and stops under different lubricating conditions

\begin{tabular}{cccccc}
\hline $\begin{array}{c}\text { Sr. } \\
\text { No. }\end{array}$ & $\begin{array}{c}\text { Bearing } \\
\text { material }\end{array}$ & $\begin{array}{c}\text { Weight before } \\
\text { wear test } \\
\text { in } \mathbf{~ g}\end{array}$ & $\begin{array}{c}\text { Weight after } \\
\text { wear test } \\
\text { in } \mathbf{~}\end{array}$ & Lubricant & $\begin{array}{c}\text { Difference } \\
\text { in } \mathbf{~ m g}\end{array}$ \\
\hline $\mathbf{1}$ & Aluminum & 56.6518 & 56.6465 & FF & 5.3 \\
$\mathbf{2}$ & Aluminum & 53.4482 & 53.4462 & ISOVG46 & 2 \\
$\mathbf{3}$ & Aluminum & 53.5720 & 53.5686 & ISOVG32 & 3.4 \\
$\mathbf{4}$ & Aluminum & 56.3836 & 56.3791 & ISOVG22 & 4.5 \\
$\mathbf{5}$ & Brass & 174.9330 & 174.9227 & FF & 10.3 \\
$\mathbf{6}$ & Brass & 186.5974 & 186.5947 & ISOVG46 & 2.7 \\
$\mathbf{7}$ & Brass & 186.1063 & 186.1013 & ISOVG32 & 5 \\
$\mathbf{8}$ & Brass & 185.0509 & 185.0434 & ISOVG22 & 7.5 \\
\hline
\end{tabular}
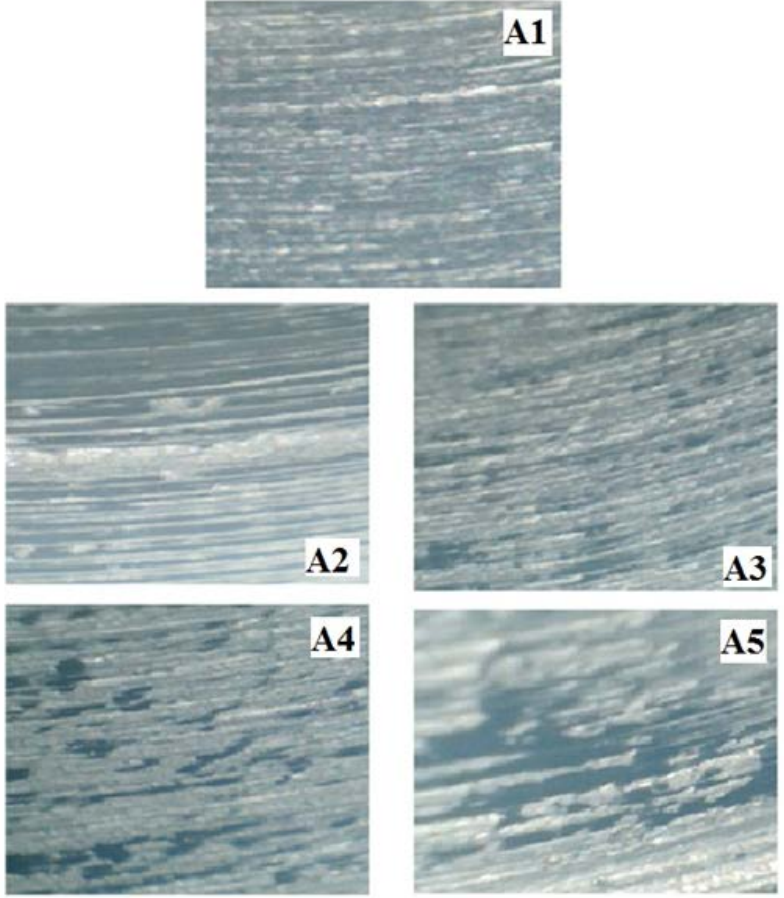

Fig. 19 Optical microscopic images of aluminum bearing surfaces. (A1) Unused surface (A2) image after 150 starts and stops under FF (A3) image after 150 starts and stops under ISOVG46 oil (A4) image after frequent starts and stops under ISOVG32 lubrication (A5) image after 150 starts and stops under ISOVG22 oil
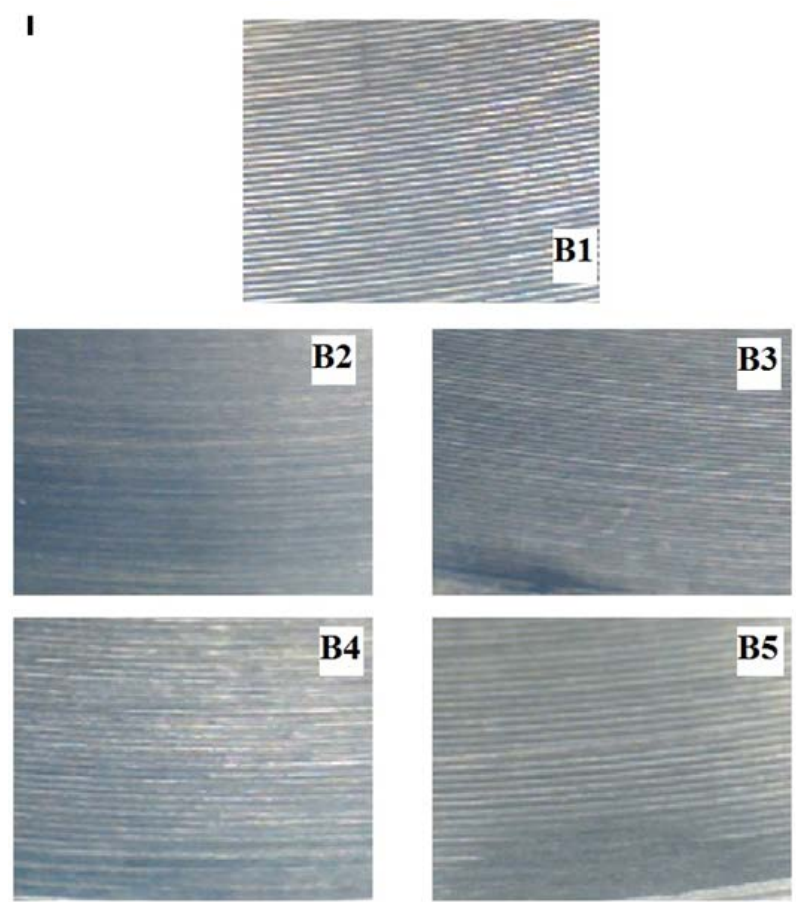

Fig. 20 Optical microscopic images of brass bearing surfaces. (B1) Unused surface (B2) image after 150 starts and stops under FF (B3) image after 150 starts and stops under ISOVG46 oil (B4) image after frequent starts and stops under ISOVG32 lubrication (B5) image after 150 starts and stops under ISOVG22 oil 
to some localized material loss from the surface as seen in Figs. 19, 20 in case of ISOVG32 and ISOVG22 fluid based system. Further, from Figs. 19, 20, it is examined that the material removal is seen maximum in the case of FF based system both in aluminum and brass bearings and minimum in ISOVG46 based bearing systems. The material removal in the case of ISOVG22 in both the cases is found nearly equal to FF based system. The more wear loss found in case of FF and ISOVG22 fluid based system may be due to improper formation of the film in the boundary lubrication region during starting and stopping of the machine.

\section{Conclusions}

In this article, tribological characteristics of the magnetic shaft made from EN-19 based journal bearing system lubricated with FF was examined and compared with various conventional lubricant based systems. The results showed that up to $84 \%$ enhancement in maximum film pressure was obtained in comparison with more viscous fluid ISOVG46 based bearing system. Besides, film pressure was measured at various operating conditions using three years old used and new FF. These results demonstrated that there was no decrement in pressure found at most of the conditions except in the boundary region. This was also confirmed by results of DLS analysis which gave almost similar particle and size distribution of the old and new FF. Thus, it can be inferred that the present bearing system may offers stable system over the long period of time. Further, from temperature analysis it was revealed that the FF based system offered almost $40 \%$ less temperature rise in the hydrodynamic region in comparison with various conventional lubricants based systems. However, marginal difference in the vibration was observed between the FF based and ISOVG46 fluid based bearing system. Moreover, the friction torque results obtained in the hydrodynamic region indicated that the friction torque offered by FF based system was significantly less even in comparison with less viscous lubricant ISOVG22. Nevertheless, the wear loss of FF based system was found marginally more in comparison with thin lubricant ISOVG22 based system. Also, the present FF based bearing system magnetic shaft was made from easily available and less costly EN-19 and may offer less wear in the low applied load and medium to high speed operating region. Thus, this analysis established that in view of cost, efficiency and stability the present bearing system may prove to be a better option for industrial applications.

\section{Acknowledgement}

The fruitful comments and suggestions of the reviewers/ editors are gratefully acknowledged by the authors.

\section{References}

[1] Papell, S. S., "Low Viscosity Magnetic Fluid Obtained by the Colloidal Suspension of Magnetic Particles," US Patent 3215572, 1965.

[2] Nuringer, J. L. and Rosensweig, R. E., "Ferrohydrodynamics," The Physics of Fluids, 7, 1964, 1927-1937.

[3] Tarapov, I. E., "Movement of a Magnetizable Fluid in the Lubricating Layer of a Cylindrical Bearing," Magnetohydrodynamics, 8, 1972, 444-448.

[4] Shliomis, M. I., "Effective Viscosity of Magnetic Suspensions," Soviet Physics JETP, 34, 1972, 1291-1294.
[5] Jenkins, J. T., "A Theory of Magnetic Fluids," Archive for Rotational Mechanics and Analysis, 46, 1972, 42-60.

[6] Sorge, F. A., "A Numerical Approach to Finite Journal Bearings Lubricated with Ferrofluid," ASME J. Tribol., 109, 1, 1987, 77-82.

[7] Chanda, P., Sinha, P. and Kumar, D., "Ferrofluid Lubrication of a Journal Bearing Considering Cavitation," Acta Mechanica, 35, 1992, 163-169.

[8] Tipei, N., "Overall Characteristics of Bearings Lubricated with Ferrofluids," Journal of Lubrication Technology, 105, 3, 1983, 466475.

[9] Chang, H. S., Chi, C. Q. and Zhao, P. Z., "A Theoretical and Experimental Study of Ferrofluid Lubricated Four-Pocket Journal Bearings," Journal of Magnetism and Magnetic Materials, 65, 2-3, 1987, 372-374.

[10] Osman, T. A., Nada, G. S. and Safar, Z. S., "Static and Dynamic Characteristics of Magnetized Journal Bearings Lubricated with Ferrofluid," Tribology International, 34, 6, 2001, 369-380.

[11] Osman, T. A., Nada, G. S. and Safar, Z. S., “Different Magnetic Models in the Design of Hydrodynamic Journal Bearings Lubricated with Non-Newtonian Ferrofluid," Tribology Letters, 14, 3, 2003, 211-223.

[12] Shah, R. C. and Bhat, M. V., "Ferrofluid Squeeze Film in a Long Journal Bearing," Tribology International, 37, 6, 2004, 441-446.

[13] Urreta, H., Leicht, Z., Sanchez, A., Agirre, A., Kuzhir, P. and Magnac, G., "Hydrodynamic Bearing Lubricated with Magnetic Fluids," Journal of Intelligent Material Systems and Structures, 21, 15, 2010, 1491-1499.

[14] Patel, N. S., Vakharia, D. P. and Deheri, G. M., "A Study on the Performance of a Magnetic-Fluid-Based Hydrodynamic Short Journal Bearing," ISRN Mechanical Engineering, 2012, 2012, 1-7.

[15] Patel, N. S., Vakharia, D. P. and Deheri, G. M., "The Performance Analysis of a Magnetic Fluid-Based Hydrodynamic Long Journal Bearing," Proceedings of International Conference on Advances in Tribology and Engineering Systems, Springer India, 2014, 117-126.

[16] Salem, L., Mohamed, E. K., Mohamed, N. and Benyebka, B.-S., “Static Characteristics of Ferrofluid Finite Journal Bearing Considering Rotational Viscosity Effect," Lubrication Science, 29, 4, 2017, 203226.

[17] Chao, P. C. P. and Huang, J. S., "Calculating Rotordynamic Coefficients of a Ferrofluid-Lubricated and Herringbone-Grooved Journal Bearing Via Finite Difference Method," Tribology Letters, 19, 2005, 101-110.

[18] Miwa, M., Harita, H., Nishigami, T., Kaneko, R. and Unozawa, H., "Frequency Characteristics of Stiffness and Damping Effect of a Ferrofluid Bearing," Tribology Letters, 15, 2, 2003, 97-105.

[19] Lin, J. R., “Dynamic Characteristics of Magnetic Fluid Based Sliding Bearings," Mechanics, 19, 2013, 554-558.

[20] Lampaent, S. G. E., Spronck, J. W. and van Ostayen, R. A. J., “Load and Stiffness of a Planar Ferrofluid Pocket Bearing," Proceedings of the Institution of Mechanical Engineers, Part J: Journal of Engineering Tribology, 232, 1, 2018, 14-25.

[21] Miyake, S. and Takahashi, S., "Sliding Bearing Lubricated with Ferromagnetic Fluid," A S L E Transactions, 28, 4, 1985, 461-466.

[22] Cheever, C. J., Li, Z. and Raj, K., "Ferrofluid Film Bearing for Enhancement of Rotary Scanner Performance," Proc. SPIE 1454, Beam Deflection and Scanning Technologies, 1991, 139-151.

[23] Li-Jun, W., Chu-Wen, G., Ryuichiro, Y. and Yue, W., "Tribological Properties of Mn-Zn-Fe Magnetic Fluids under Magnetic Field," Tribology International, 42, 6, 2009, 792-797.

[24] Huang, W., Shen, C. and Wang, X., "Study on Static Supporting Capacity and Tribological Performance of Ferrofluids," Tribology Transactions, 52, 5, 2009, 717-723.

[25] Andablo-Reyes, E., Hidalgo-Alvarez, R. and de Vicente, J., 
"Controlling Friction Using Magnetic Nanofluids," Soft Matter, 7, 3 , 2011, 880-883.

[26] Jianmei, W., Jianfeng, K., Yanjuan, Z. and Xunjie, H., “Viscosity Monitoring and Control on Oil-Film Bearing Lubrication with Ferrofluids," Tribology International, 75, 2014, 61-68.

[27] Patel, N. S., Vakharia, D. and Deheri, G., "Hydrodynamic Journal Bearing Lubricated with a Ferrofluid," Industrial Lubrication and Tribology, 69, 5, 2017, 754-760.

[28] Patel, N. S., Vakharia, D. P., Deheri, G. M. and Patel, H. C., “Experimental Performance Analysis of Ferrofluid Based Hydrodynamic Journal Bearing with Different Combination of Materials," Wear, 376-377, Part B, 2017, 1877-1884.

[29] Ducom Instruments Pvt. Ltd., Journal Bearing Test Rig TR-60, Intruction Manual, 20-26.

[30] Czichos, H., Tribology: A Systems Approach to the Science and Technology of Friction, Lubrication, and Wear, Elsevier Scientific
Publishing Company, Amsterdam, 1978.

[31] Blau, P. J., "Friction Science and Technology: From Concepts to Applications," CRC Press, Taylor \& Francis Group, New York, 2009.

[32] Yarahmadi, M., Moazami Goudarzi, H. and Shafii, M. B., "Experimental Investigation into Laminar Forced Convective Heat Transfer of Ferrofluids under Constant and Oscillating Magnetic Field with Different Magnetic Field Arrangements and Oscillation Modes," Experimental Thermal and Fluid Science, 68, 2015, 601-611.

[33] Bouyer, J., Fillon, M. and Pierre-Danos, I., "Influence of Wear on the Behavior of a Two-Lobe Hydrodynamic Journal Bearing Subjected to Numerous Startups and Stops," Journal of Tribology, 129, 1, 2007, 205-208.

[34] Durak, E., Adatepe, H. and Biyiklioglu, A., "Experimental Study of the Effect of Additive on the Tribological Properties Journal Bearing under Running-in and Start-Up or Shut-Down Stages," Industrial Lubrication and Tribology, 60, 3, 2008, 138-146.
This paper is licensed under the Creative Commons Attribution-NonCommercial-NoDerivatives 4.0 International (CC BY-NC-ND 4.0) International License. This allows users to copy and distribute the paper, only upon conditions that (i) users do not copy or distribute such paper for commercial purposes, (ii) users do not change, modify or edit such paper in any way, (iii) users give appropriate credit (with a link to the formal publication through the relevant DOI (Digital Object Identifier)) and provide a link to this license, and (iv) users acknowledge and agree that users and their use of such paper are not connected with, or sponsored, endorsed, or granted official status by the Licensor (i.e. Japanese Society of Tribologists). To view this license, go to https://creativecommons.org/licenses/by-nc-nd/4.0/. Be noted that the third-party materials in this article are not included in the Creative Commons license, if indicated on the material's credit line. The users must obtain the permission of the copyright holder and use the third-party materials in accordance with the rule specified by the copyright holder. 